\title{
Surgical resection of circumferential epicardial adipose tissue hypertrophy: Case report and systematic review of the literature
}

\author{
Hassiba Smail, MD, ${ }^{\mathrm{a}}$ Andrei Baciu, MD, ${ }^{\mathrm{a}}$ Jean-Nicolas Dacher, $\mathrm{MD}, \mathrm{PhD},{ }^{\mathrm{b}}$ and \\ Pierre-Yves Litzler, MD, PhD, ${ }^{a}$ Rouen, France
}

\footnotetext{
From the Departments of ${ }^{\mathrm{a}}$ Thoracic and Cardiovascular Surgery, and ${ }^{\mathrm{b}}$ Radiology, Rouen University Hospital Charles Nicolle, Rouen, France.

Disclosures: Authors have nothing to disclose with regard to commercial support.

Received for publication June 19, 2015; revisions received Aug 5, 2015; accepted for publication Aug 21, 2015; available ahead of print Sept 20, 2015.

Address for reprints: Hassiba Smail, MD, Department of Thoracic and Cardiovascular Surgery, Rouen University Hospital Charles Nicolle, 1, rue de Germont, 76000 Rouen, France (E-mail: Hassibasmail@yahoo.fr).

J Thorac Cardiovasc Surg 2016;151:e27-30 $0022-5223 / \$ 36.00$

Copyright (C) 2016 by The American Association for Thoracic Surgery http://dx.doi.org/10.1016/j.jtcvs.2015.08.083
}

\section{Video clip is available online.}

\section{CLINICAL SUMMARY}

A 53-year-old woman with a medical history of metabolic syndrome and long-term nasal corticosteroid treatment was admitted for suspicion of acute coronary syndrome. The patient described recurrent chest pain and severe dyspnea. On examination, she presented a muffled heart sound with left pulmonary dullness and fever $\left(38.5^{\circ} \mathrm{C}\right.$ ). Her body mass index was $31.6 \mathrm{~kg} / \mathrm{m}^{2}$ (weight: $75 \mathrm{~kg}$, height: $154 \mathrm{~cm}$ ) with a loss of $16 \mathrm{~kg}$ during the last 6 months. The electrocardiogram was normal, and chest $\mathrm{x}$-ray revealed a left pleural effusion. Biological data showed an inflammatory profile and a normal troponin. Transthoracic echocardiography (TTE) showed images of moderate pericardial effusion $(20 \mathrm{~mm})$. Coronary angiography results were normal. Aside from a minimal elevation of the pulmonary artery pressure (systolic/diastolic mean) 36/25-31 mm Hg, right heart catheterization values were normal: mean pulmonary right atrial pressure was $9 \mathrm{~mm}$ $\mathrm{Hg}$, right ventricular pressure (systolic/protodiastolic-telediastolic) was 39/4-12 $\mathrm{mm} \mathrm{Hg}$, pulmonary arteriolar vascular resistance was 1.8 Wood units, and systemic vascular resistance was 13.8 Wood units. On chest computed tomography (CT) scan, pericardial fat deposits and pericardial effusion of $2 \mathrm{~cm}$ were shown. Cardiovascular magnetic resonance (CMR) was performed, revealing a thick layer of circumferential epicardial fat pad measuring up to $30 \mathrm{~mm}$ and hypertrophy of the atrial septum (25 mm) with a typical dumbbell-shaped appearance (Figure 1, $A$ and $B$ ). CMR showed severe muscle atrophy, but it did not confirm pericardial effusion. Functional data showed that epicardial adipose tissue (EAT) affected diastolic cardiac function. Thus, a diagnosis of EAT

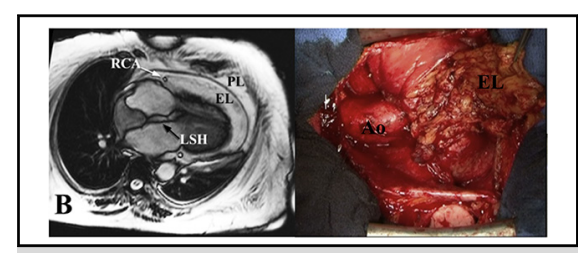

Surgical resection of the epicardial lipomatous. $R C A$ Right coronary artery; $P L$, pericardial lipomatous; $E L$, epicardial lipomatous; $L S H$, lipomatous septal hypertrophy; Ao, aorta.

\section{Central Message}

The diagnosis of CLH can be misinterpreted We performed a surgical resection with an excellent result.

See Editorial Commentary page e31.

hypertrophy with concomitant lipomatous hypertrophy of the interatrial septum (LHIS) was made, both concurring with cardiac lipomatous hypertrophy (CLH).

Because of the occurrence of a tamponade leading to a severe dyspnea and recurrent chest pain, we decided to perform a decompressive pericardiectomy and a surgical excision of the excess epicardial fat.

After a median sternotomy, the pericardium was incised and the heart swelled out. There was a circumferential fatty tissue deposit around the heart that concealed the contraction. We created a cleavage plane between the epicardial fat and the myocardium by alternatively using a low level of electrocauterization and a soft swab stick to avoid any coronary lesions (Video 1). We resected the epicardial fat carefully on the right atrium, right ventricle, aorta, and pulmonary artery (Video 1). On the left ventricle, the resection was limited to the front side excluding the lateral and posterior wall. The whole procedure was performed without cardiopulmonary bypass considering the high risk of bleeding.

After surgery, the patient was extubated at 6 hours postoperatively, with an uneventful stay in the intensive care unit of 3 days. The symptoms quickly disappeared during the early postoperative period, and the patient was discharged at 7 days postoperatively.

TTE at discharge showed an ejection fraction of $62 \%$; histology confirmed benign EAT, and pleural fluid was nonspecific. One month after surgery, CMR showed a significant decrease of the epicardial fat volume $(15 \mathrm{~mm})$ and correct diastolic function. The patient stopped the 


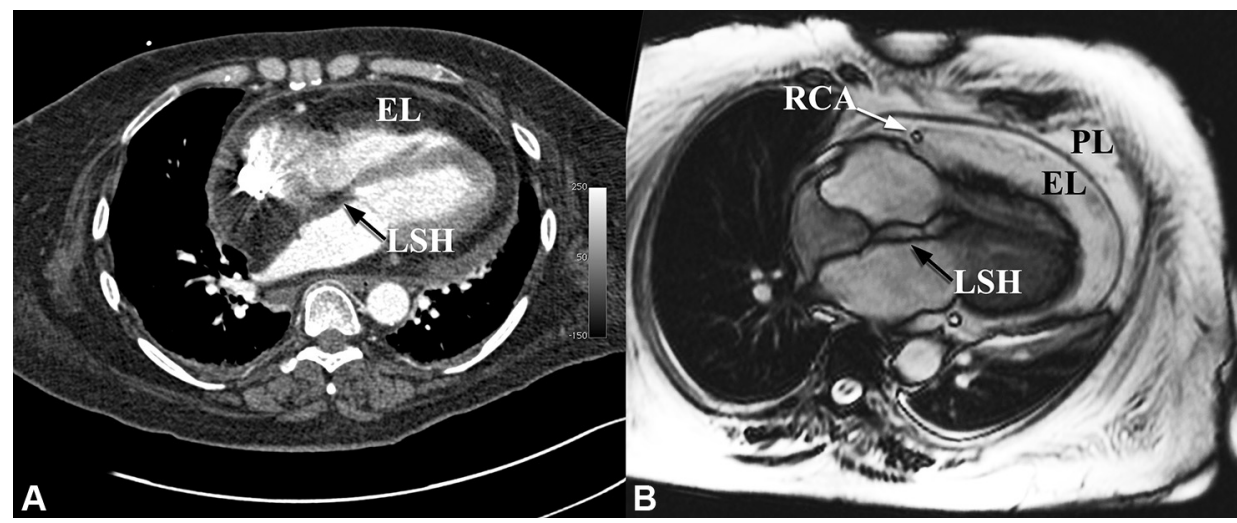

FIGURE 1. Preoperative chest CT scan (A) and CMR images (B). Images showing extensive epicardial lipomatous hypertrophy and LHIS. EL, Epicardial lipomatous; $L S H$, lipomatous septal hypertrophy; $R C A$, right coronary artery; $P L$, pericardial lipomatous.

corticosteroid therapy, and better control of the metabolic syndrome was initiated.

Three years after surgery, the patient remains asymptomatic from chest pain and dyspnea. CMR showed stable epicardial fat volume $(15 \mathrm{~mm})$ and stable morphology of the LHIS (Figure 2).

\section{SYSTEMATIC REVIEW METHOD \\ Search Strategy}

We searched 3 databases (PubMed, Medline, and Embase) in an attempt to locate all existing English-language case reports on the surgical management of epicardial fat hypertrophy with acute presentation of diastolic dysfunction. Search terms were "epicardial lipomatous hypertrophy" or "epicardial adipose tissue hypertrophy" or "cardiac lipomatous hypertrophy." These terms were combined with "diastolic dysfunction," "tamponade," and "surgical resection."

\section{Inclusion and Exclusion Criteria}

Only original case reports of surgical management of EAT hypertrophy with acute presentation of diastolic

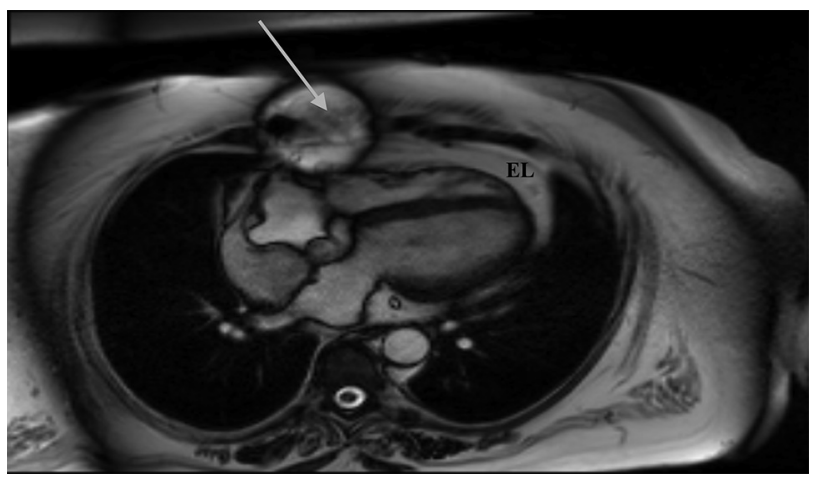

FIGURE 2. CMR imaging at 3-year follow-up showing stability of epicardial lipomatous hypertrophy $(15 \mathrm{~mm})$ compared with immediate postoperative CMR imaging (arrow: metallic artefact from a sternal wire). EL, Epicardial lipomatous. dysfunction or tamponade were included in this review. We excluded all literature reviews, clinical trial articles, and all analyses of LHIS. Two authors independently screened the titles and abstracts of all articles found in the initial search.

\section{Data Extraction}

We extracted the author, year of publication, age, clinical presentation, imaging diagnosis, and treatment, when provided.

\section{RESULTS}

By using the predefined strategy, as indicated by the Preferred Reporting Items for Systematic review and meta-Analysis protocol, ${ }^{1} 236$ references were retrieved for initial screening, of which a total of 233 were excluded (Figure 3). Of the remaining 3 case reports, only 2 met our inclusion criteria. The patient and surgical characteristics from these 2 case reports ${ }^{2,3}$ are summarized in Table 1. Our systematic review did not identify any published description of surgical resection of epicardial fat.

\section{DISCUSSION}

CLH is not a well-known cardiac pathology, and its diagnosis remains difficult; nevertheless, the anatomic and radiologic descriptions in our case confirmed a diagnosis of EAT hypertrophy with concomitant LHIS. CLH is defined as an infiltration of fat within the interatrial septum and an increase of the EAT thickness. ${ }^{4}$

Our systematic review identified that the most frequently published anatomic expression of $\mathrm{CLH}$ is LHIS (137 articles). It is characterized by excessive fat deposition in the interatrial septum and a thickness of more than $20 \mathrm{~mm}$. The diagnosis of LHIS is most often made incidentally or during arrhythmia. Imaging diagnosis consists of the typical dumbbell-shaped appearance of the interatrial septum, and LHIS is associated with hypertrophy of EAT in $75 \%$ of cases. ${ }^{5,6}$ In our case, the 

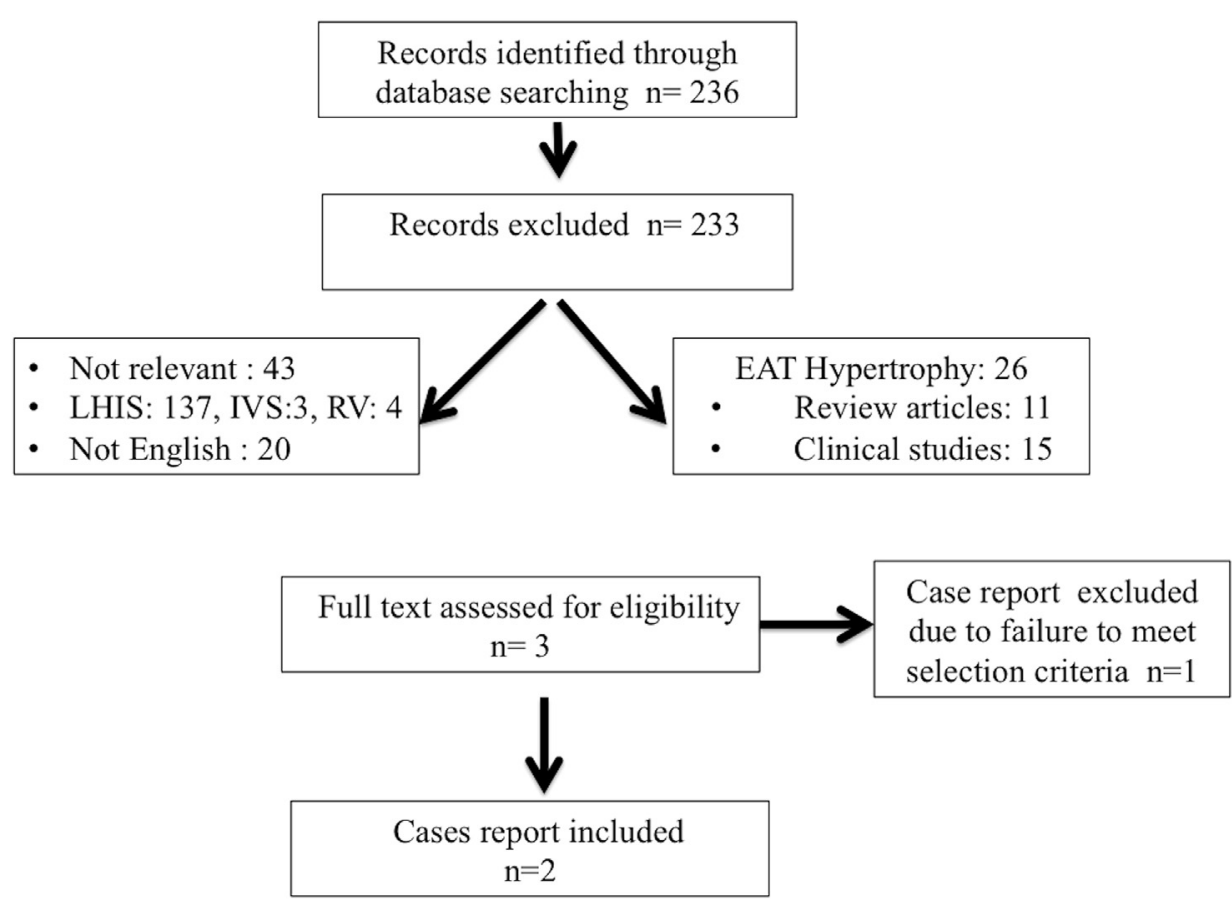

FIGURE 3. Preferred Reporting Items for Systematic Reviews and Meta-Analysis flow chart summarizing the search method. LHIS, Lipomatous hypertrophy of the interatrial septum; IVS, interventricular septum; $R V$, right ventricle; $E A T$, epicardial adipose tissue.

symptoms mimicked an acute coronary syndrome, although no significant epicardial coronary artery stenosis was present. In patients with EAT hypertrophy who presented with angina-like chest pain and angiographically normal coronary arteries, Sade and colleagues ${ }^{7}$ related the chest pain to microvascular angina caused by reduced coronary blood flow reserve.

In addition to the chest pain, our patient also presented shortness of breath and a moderate elevation of pulmonary arterial pressure that simulated a cardiac tamponade. Only 3 case reports of similar presentations were found in our review; however, the clinical diagnosis of EAT hypertrophy was misrepresented as cardiomegaly in dry-weight assessment of a patient on dialysis ${ }^{8}$ and as pericardial effusion and tamponade in 2 other patients ${ }^{2,3}$ (Table 1).

The clinical trials found during this review described the imaging tools used for diagnosis of EAT hypertrophy. TTE is the most used cardiac imaging to determine the EAT thickness, which varies from 1 to $23 \mathrm{~mm}$, with a median of $7 \mathrm{~mm}$ in men and $6.5 \mathrm{~mm}$ in women. ${ }^{9}$ In our patient, the TTE and the chest CT scan initially pointed to a pericardial effusion diagnosis. Tissue characterization as provided by CMR allowed the accurate diagnosis of EAT hypertrophy (30 $\mathrm{mm}$ thickness in our case) associated with LHIS. Because of its high signal intensity, CMR is known to be particularly accurate for assessing pericardial disease and

TABLE 1. Summary of included case reports (identified in systematic review) with diastolic dysfunction and tamponade related to epicardial adipose tissue hypertrophy

\begin{tabular}{|c|c|c|c|c|c|}
\hline $\begin{array}{c}\text { Reference and } \\
\text { year of publication }\end{array}$ & $\begin{array}{l}\text { Patient details } \\
\text { and clinical } \\
\text { presentation } \\
\end{array}$ & Diagnosis & $\begin{array}{c}\text { Associated } \\
\text { LHIS } \\
\end{array}$ & Treatment & Outcome \\
\hline $\begin{array}{l}\text { Miller and colleagues }{ }^{2} \\
2011\end{array}$ & $\begin{array}{l}\text { 62-year-old man with } \\
\text { exertional dyspnea }\end{array}$ & $\begin{array}{l}\text { TTE: pericardial effusion } \\
\text { CMR: epicardial lipomatous } \\
\text { hypertrophy } \\
\text { Normal cardiac function }\end{array}$ & Yes & $\begin{array}{l}\text { No surgical } \\
\text { management }\end{array}$ & Not described \\
\hline $\begin{array}{l}\text { Myerson and } \\
\text { colleagues }^{3} 2004\end{array}$ & $\begin{array}{l}\text { 72-year-old woman with } \\
\text { shortness of breath }\end{array}$ & $\begin{array}{l}\text { TTE: chronic pericardial } \\
\text { effusion } \\
\text { CMR: CLH } \\
\text { Impaired diastolic filling: } \\
\text { tamponade }\end{array}$ & Yes & $\begin{array}{l}\text { Surgical management: } \\
\text { decompressive } \\
\text { pericardiectomy }\end{array}$ & $\begin{array}{l}\text { Asymptomatic } \\
\text { after } 1 \mathrm{y}\end{array}$ \\
\hline
\end{tabular}

$\overline{L H I S, \text { Lipomatous hypertrophy of the interatrial septum; TTE, transthoracic echocardiography; CMR, cardiovascular magnetic resonance; } C L H \text {, cardiac lipomatous hypertrophy. }}$ 
identifying adipose tissue; moreover, CMR can evaluate cardiac function. ${ }^{2,10}$

Despite the increased diagnosis of EAT hypertrophy with the widespread use of CT and CMR, the knowledge of its pathologic implication remains partial. ${ }^{11}$ The clinical studies and reviews have shown that EAT hypertrophy is associated with metabolic syndrome, including a significant correlation with low-density lipoprotein cholesterol, fasting insulin, adiponectin, and arterial blood pressure. ${ }^{12,13}$ EAT hypertrophy may be implicated in the pathogenesis of coronary artery disease, mediating the inflammatory process within the atherosclerotic plaque. ${ }^{14}$ It has also been associated with changes in left and right ventricular mass and diastolic function. ${ }^{15}$

The limited published literature identified in our review indicates that the management of asymptomatic hypertrophy of EAT is not well documented. Exercise, statins, and weight loss have been identified as beneficial. ${ }^{16}$ To our knowledge, the surgical resection of epicardial tissue in EAT hypertrophy has never been described. We resected the excess EAT to avoid recurrent chest pain and fat tamponade, although we did not resect the epicardial fat on the posterior wall of the heart because the patient's hemodynamic condition was not sufficient to support the tilt of the heart or the use of cardiopulmonary bypass. We found only 1 case report of a pericardiectomy in a patient with fat tamponade and diastolic dysfunction; however, no epicardial fat resection was described in this case (Table 1).

Previous reports of CLH have focused mainly on the surgical resection of the interatrial fat. ${ }^{17}$ The indications include intractable arrhythmia and obstruction of the superior vena cava. ${ }^{18}$ In the absence of those complications in our patient, we declined any surgical procedure on the interatrial septum. The surgical procedure of epicardial excision could be considered as invasive because of the high risk of coronary artery injury. The surgery was performed without complications, and the patient made an uncomplicated recovery. Clinical and CMR long-term follow-up at 3 years was uneventful.

\section{CONCLUSIONS}

This case and our systematic review highlight the difficulty of CLH diagnosis and the possibility of misdiagnosis as tamponade or an acute coronary syndrome. The surgical resection of the circumferential EAT hypertrophy has never been described; nevertheless, it was performed successfully with an excellent long-term result.

\section{References}

1. Shamsser L, Moher D, Clarke M, Ghersi D, Liberati A, Petticrew M, et al. Preferred reporting items for systematic review and meta-analysis protocols (PRISMA-P) 2015: elaboration and explanation. BMJ. 2015;349:7647.

2. Miller CA, Schmitt M. Epicardial lipomatous hypertrophy mimicking pericardial effusion characterization with cardiovascular magnetic resonance. Circ Cardiovasc Imaging. 2011;4:77-8.

3. Myerson SG, Roberts R, Moat N, Pennell DJ. Tamponade caused by cardiac lipomatous hypertrophy. J Cardiovasc Magn Reson. 2004;6:565-8.

4. Sacks HS, Fain JN. Human epicardial fat: what is new and what is missing? Clin Exp Pharmacol Physiol. 2011;38:879-87.

5. Shirani J, Roberts WC. Clinical, electro-cardiographic and morphologic features of massive fatty deposits in the atrial septum. J Am Coll Cardiol. 1993;22: 226-38.

6. Heyer CM, Kagel T, Lemburg SP, Bauer TT, Nicolas V. Lipomatous hypertrophy of the interatrial septum: a prospective study of incidence, imaging findings, and clinical symptoms. Chest. 2003;124:2068-73.

7. Sade LE, Eroglu S, Bozbas H, Ozbicer S, Hayran M, Haberal A, et al. Relation between epicardial fat thickness and coronary flow reserve in women with chest pain and angiographically normal coronary arteries. Atherosclerosis. 2009;204: 580-5.

8. Kircelli F, Gunduz M, Gungor O, Ercan OK. Excess epicardial fat mass misrepresented as cardiomegaly in dry-weight assessment of a dialysis patient. Hemodial Int. 2012;16:435-7.

9. Iacobellis G, Willens HJ. Echocardiographic epicardial fat: a review of research and clinical applications. J Am Soc Echocardiogr. 2009;22:1311-9.

10. Nelson AJ, Worthley MI, Psatltis PJ, Carbone A, Dundon BK, Duncan RF, et al Validation of cardiovascular magnetic resonance assessment of pericardial adipose tissue volume. J Cardiovasc Magn Reson. 2009;11:15.

11. Iacobellis G, Corradi D, Sharma AM. Epicardial adipose tissue: anatomic, biomolecular and clinical relationship with the heart. Nat Clin Pract Cardiovasc Med. 2005;2:536-43.

12. Bachar GN, Dicker D, Kornowski R, Atar E. Epicardial adipose tissue as a predictor of coronary artery disease in asymptomatic subjects. Am J Cardiol. 2012; $110: 534-8$

13. Pierdomenico SD, Pierdomenico AM, Cuccurullo F, Iacobellis G. Meta-analysis of the relation of echocardiographic epicardial adipose tissue thickness and the metabolic syndrome. Am J Cardiol. 2013;111:73-8.

14. Iacobellis G, Bianco AC. Epicardial adipose tissue: emerging physiological, pathophysiological and clinical features. Trends Endocrinal Metab. 2011;22: 450-7.

15. Iacobellis G, Ribaudo MC, Zappaterreno A, Iannucci CV, Leonetti F. Relation between epicardial adipose tissue and left ventricular mass. Am J Cardiol. 2004;94:1084-7.

16. Whayne TF. Epicardial fat thickness in heart failure and other clinical conditions. Angiology. 2012;64:169-72.

17. Doesch C, Plachtzik C, Haas CS. Lipomatous septal hypertrophy. J Thorac Cardiovasc Surg. 2009;137:e3-4.

18. Zeebregts CJ, Hensens AG, Timmermans J, Prusczczynski MS, Lacquet LK. Lipomatous hypertrophy of the interatrial septum: indications for surgery? Eur J Cardiothorac Surg. 1997;11:785-7. 